Research Article

\title{
Fluorescence Spectroscopy and ${ }^{13} \mathrm{C}$ NMR Spectroscopy Characteristics of HA in Black Soil at Different Corn Straw Returning Modes
}

\author{
Shuang Zheng, Sen Dou (D), HongMei Duan, BoYan Zhang, and Yue Bai \\ College of Resource and Environmental Science, Jilin Agricultural University, Changchun 130118, Jilin Province, China \\ Correspondence should be addressed to Sen Dou; dousen1959@126.com
}

Received 7 March 2021; Revised 21 May 2021; Accepted 31 May 2021; Published 7 June 2021

Academic Editor: Valentina Venuti

Copyright (C) 2021 Shuang Zheng et al. This is an open access article distributed under the Creative Commons Attribution License, which permits unrestricted use, distribution, and reproduction in any medium, provided the original work is properly cited.

\begin{abstract}
A three-year field experiment was conducted to analyze the effects of straw enrichment and deep incorporation on the humus composition and the structure of humic acid (HA) in black soil. The differences in the HA structure between different straw returning methods were detected by three-dimensional fluorescence spectroscopy and ${ }^{13} \mathrm{C}$ NMR technology. The purpose of this paper is to provide a theoretical basis and data support for improving the straw returning system. Four different treatments, including no straw applied (CK), straw mulching (SCR), straw deep ploughing (MBR), and straw enrichment and deep incorporation (SEDI: harvested the corn straw from four rows together with a finger-plate rake and then crushed and buried them in one row in the 20 40 cm deep level in the subsoil with a wind-driven input cylindrical plough), were used in this study. Our results showed that compared to CK treatment, SEDI significantly increased the contents of organic carbon (SOC), soil humic acid carbon (HAC), fulvic acid carbon (FAC), and humin C content (HM-C) in the subsurface soil layer by $27.47 \%, 34.33 \%, 19.66 \%$, and $31.49 \%$, respectively. Among all the straw returning treatments, SEDI treatment had the most significant effect in increasing the contents of HEC, HAC, and FAC. Straw returning not only reduced the degree of condensation and oxidation of the HA structure but also increased the proportion of alkyl $\mathrm{C}$ and enhanced the hydrophobicity of the HA structure in subsurface soil. Moreover, SEDI treatment significantly increased the proportion of aliphatic C/aromatic C of the HA structure in subsurface soil and improved the aliphatic property of HA, which had a significant effect on the HA structure compared to other treatments.
\end{abstract}

\section{Introduction}

In recent years, due to long-term intensive agricultural production and soil erosion, the soil organic content and humus quality of black soil have decreased significantly in Northeast China, resulting in shallower soil layers [1] and poor cultivability of land. Moreover, corn straw incorporation was effective in increasing soil organic carbon [2] and humus $\mathrm{C}$ content [3], deepening the degree of soil humification [4], and improving the HA structure. Chen et al. showed that straw returning increases the aliphatic group of HA molecular structure, reduces the degree of condensation and oxidation of HA structure, and makes HA structure more lipidic and simple [5].

Soil organic carbon (SOC) pool is the largest terrestrial carbon pool, and $70-80 \%$ of SOC is composed of humus [6].
Humic acid (HA) is the main component of humus [7]. Furthermore, the composition, structure, and properties of HA were related to the fertilization characteristics of the soil. Returning straw to the field can improve soil fertility and increase the content of soil organic matter. Different straw returning methods have different effects on the composition of soil humus and the structure of HA. Studies have shown that straw mulching is beneficial to the accumulation of organic carbon and humic substance $\mathrm{C}$ content [8] and the enhancement of functional groups such as aliphatic, hydroxyl, methoxy, and carboxyl groups on the surface soil [9], but straw mulching also affects seedling emergence and makes tillage difficult [10]. A new straw returning method had been developed, namely, straw enrichment and deep incorporation (SEDI), consisting in (1) raking the corn stalk in the field together into rows at a ratio of $4: 1$ with a 
finger-plate rake; (2) crushing the corn straw and burying it into subsoil, $20 \sim 40 \mathrm{~cm}$ deep along designated strips with a wind-driven input cylindrical plough; (3) sowing seeds into the strips with no straw buried in between the strips with straw buried in a normal way with a nontillage seeder, to realize separation of the seeded strips (narrow rows) from the strips (wide rows) with straw buried in a wide-andnarrow row alternating cultivation mode. Zuber et al. showed that straw deep ploughing has a better effect on the accumulation of soil organic matter than that of straw mulching [11] and also increases the organic carbon content of HE and HA [12]. Straw deep incorporation can also significantly increase the content of soil subsurface active organic carbon [13], deepen the degree of soil humification [14], reduce the degree of HA structure condensation and oxidation, and increase the content of aliphatic chain hydrocarbons and aromatic carbon. Zhang et al. have shown that straw deep incorporation accumulates soil organic carbon and humus component carbon content in different soil layers and improved the aromaticity and hydrophobicity of HA molecules [15]. Al et al. compared the changes in the structure of soil humic acid after applying crop straw, jujube leaf, and animal manure by solid-state- ${ }^{13} \mathrm{C}$ NMR. Their results indicated that crop straw has the highest aliphatic content and the strongest aliphatic content [16]. Chen $\mathrm{Xi}$ et al. showed that straw returning could increase the relative content of alkoxy carbon in soil organic carbon through ${ }^{13} \mathrm{C}$ NMR research [17].

Nowadays, three-dimensional fluorescence spectroscopy and ${ }^{13} \mathrm{C}$ NMR techniques were used to study the effects of straw returning on humic composition and HA structure. Previous research mainly focused on straw mulching and straw shallow application on the accumulation of soil organic carbon and humus $\mathrm{C}$ in the surface layer [8]. However, the effects of straw enrichment and deep incorporation (SEDI) on soil humus composition and HA structure are yet poorly understood, along with the differences of HA structure between SEDI and other returning methods. To address the issue, we conducted a 3-year field experiment to (i) determine the SOC content, (ii) characterize humus composition and $\mathrm{C}$ content, and (iii) compare the changes of HA structure from different return methods by three-dimensional fluorescence spectroscopy and ${ }^{13} \mathrm{C}$ CPMAS NMR technology. In order to provide a theoretical basis and data support for the improvement of straw returning system, this paper focused on discussing the impact of the hydrophilicity and hydrophobicity of the HA structure on soil stability.

\section{Materials and Methods}

2.1. Experimental Site. The experiment was located at the Experimental Station of Agricultural Technology Extension Center in Jiutai District, Changchun City, Jilin Province $\left(44^{\circ} 08^{\prime} \mathrm{N}, 125^{\circ} 50^{\prime} \mathrm{E}\right)$. The experimental soil was classified as Argiudolls. The basic properties of the sampled soil are shown in Table 1.

2.2. Experimental Design. The experiment adopted wideand-narrow row planting. The ridge height was $12 \mathrm{~cm}$, and the row spacing was $40 \mathrm{~cm}$. The planting density was $65000 /$ $\mathrm{hm}^{2}$. Four treatments were set randomly with three replications. CK: no straw was applied; SCR: corn straw was evenly placed on the soil surface; MBR: corn straw was evenly placed on the soil surface, and straw deep turning and returning to the field to $25-30 \mathrm{~cm}$ soil layer; SEDI: the corn straw was harvested from four rows together with a fingerplate rake and then crushed and buried them in one row in the $20 \sim 40 \mathrm{~cm}$ deep level in the subsoil with a wind-driven input cylindrical plough. The corn straw was mechanically crushed in all three corn straw treatments. The experiment selected field planting; each treatment area was $1334 \mathrm{~m}^{2}$. Each plot had the same fertilizer application rate: $200 \mathrm{~kg} \cdot \mathrm{N} \cdot \mathrm{ha}^{-1}, 100 \mathrm{~kg} \cdot \mathrm{k} \cdot \mathrm{ha}^{-1}$, and $100 \mathrm{~kg} \cdot \mathrm{Pha}^{-1}$.

2.3. Soil Sampling and Analysis. Soil samples were collected after the maize harvest in November 2019. For each treatment, the soil samples were collected from three points in each plot replicate. The sampling depth was $0-20 \mathrm{~cm}$ and $20-40 \mathrm{~cm}$. Each soil sample was air-dried and passed through a $2 \mathrm{~mm}$ sieve to remove plant residues for extracting soil HA.

2.4. Laboratory Analysis. SOC was determined using the $\mathrm{K}_{2} \mathrm{Cr}_{2} \mathrm{O}_{7}$ external heating method. Alkalytic $\mathrm{N}$ was measured using the alkali diffusion method; available $\mathrm{P}$ was measured using sodium bicarbonate-molybdenum antimony colorimetry; available $\mathrm{K}$ was measured using a flame photometer, which was measured by a $\mathrm{pH}$ meter [18].

Humus composition was analyzed following the International Humic Substances Society method [19]. Briefly, $5 \mathrm{~g}$ of soil sample was sequentially extracted with $30 \mathrm{~mL}$ of distilled water, then with $30 \mathrm{~mL}$ of $0.1 \mathrm{~N}$ mixed alkali solution $\left(\mathrm{NaOH}+\mathrm{Na}_{4} \mathrm{P}_{2} \mathrm{O}_{7}\right)$ under continuous shaking at $70{ }^{\circ} \mathrm{C}$ for one hour. The supernatant was humic extractable (HE) substance. $30 \mathrm{~mL} \mathrm{HE}$ was acidified to $\mathrm{pH} 1$ to separate HA from humic fulvic (FA). The precipitation was retained as $\mathrm{HA}$ and FA remained in the solution. HA was redissolved with $0.05 \mathrm{~mol} \cdot \mathrm{L}^{-1} \mathrm{NaOH}$.

$\mathrm{HA}$ isolation and purification were processed using the procedure described by the International Humic Substances Society procedure described by Kuwatsuka et al. [20]. Briefly, $50 \mathrm{~g}$ of soil sample was decalcified with $\mathrm{HCl}$; then, residues were extracted by $\mathrm{NaOH}$ solution and allowed to stand overnight. The supernatant was soaked in a mixture of $\mathrm{HF}$ and HCL solution to remove ash, dialysed to electrodialysis, and freeze-dried afterwards.

2.5. Characterization of HA. HA element composition, such as $\mathrm{C}, \mathrm{H}, \mathrm{N}$, and $\mathrm{O}$, was determined by a Vario EL III elemental analyzer. The fluorescence spectra were obtained at a concentration of $100 \mathrm{mg} \mathrm{L}^{-1}(\mathrm{pH}$ was adjusted to 8.0 with $0.05 \mathrm{M} \mathrm{NaOH})$. The EEM spectra were recorded with emission wavelength between 300 and $600 \mathrm{~nm}$, while the excitation wavelength was increased sequentially from 250 to $550 \mathrm{~nm}$. The emission-excitation slit was fixed at the $5 \mathrm{~nm}$ bandwidth and the scanning speed was set at 
TABLE 1: Basic properties of the tested soil.

\begin{tabular}{lcccc}
\hline Depth $(\mathrm{cm})$ & Organic matter $(\mathrm{g} / \mathrm{kg})$ & Total N $(\mathrm{mg} / \mathrm{kg})$ & Available $\mathrm{P}(\mathrm{mg} / \mathrm{kg})$ & Available $\mathrm{K}(\mathrm{mg} / \mathrm{kg})$ \\
\hline $0 \sim 20$ & 12.20 & 78.73 & 95.86 & 235.80 \\
$20 \sim 40$ & 12.05 & 76.52 & 70.17 & 204.75 \\
\hline
\end{tabular}

$12,000 \mathrm{~nm} \mathrm{~min}{ }^{-1}$. The solid-state ${ }^{13} \mathrm{C}$ NMR spectra of soil samples were obtained on an AVANCE III 400 WB spectrometer at $100.6 \mathrm{MHz}$ with a spinning rate of $8 \mathrm{kHz}$, an acquisition time of $34 \mathrm{~ms}$, a recycle time of $5 \mathrm{~s}$, and a contact time of $2 \mathrm{~ms}$. Chemical shift values were externally referenced to the methylene resonance of the adamantane standard at $38.4 \mathrm{ppm}$. Semiquantification was performed by integration using Mestre Nova 14.0 software [21].

2.6. Statistical Analysis. Analysis of variance was performed using SPSS 21.0 software. Statistical significance differences among corn straw returning mode means were evaluated using the least significant difference test at a level of $p<0.05$.

\section{Results}

3.1. SOC and Humic C. Data on the C contents of soil for each treatment are presented in Figure 1. Compared with CK treatment, SCR, MBR, and SEDI treatments increased SOC content in the surface soil layer by $12.65 \%, 10.07 \%$, and $8.38 \%$, respectively. In the $20-40 \mathrm{~cm}$ soil depth, the SOC contents increased in the following trend: SEDI $>$ MBR $>$ SCR $>$ CK. All corn straw treatments increased SOC content in the subsurface soil layer by $2.89 \%$, $18.29 \%$, and $27.47 \%$. Thus, it could be seen that for the different straw returning treatments, the SEDI had a more significant cumulative effect on the subsurface organic carbon content.

Data on the humic fractions for each treatment are presented in Table 2. For the humic fractions, SEDI treatment significantly increased the content of humic fraction (HEC) in the $20-40 \mathrm{~cm}$, soil humic acid carbon (HAC), fulvic acid carbon (FAC), and humin C content (HM-C) by $34.33 \%$, $19.66 \%$, and $31.49 \%$, respectively, compared with CK. PQ value is the proportion of HA in humic substances, which can reflect the degree of humification of SOC. Compared with $\mathrm{CK}$, the treatment of straw returning to the field increased the PQ value of the soil to varying degrees. The SEDI treatment increased the PQ value of subsurface soil the most, which increased from $62.71 \%$ to $65.39 \%$ compared with CK.

3.2. Elemental Composition of $H A$. It can be seen from Table 3 that the elements of HA are mainly composed of $\mathrm{C}$ and $\mathrm{O}$, in which the $\mathrm{C}$ content ranges from $482.1 \mathrm{~g} \mathrm{~kg}^{-1}$ to $512.9 \mathrm{~g} \mathrm{~kg}^{-1}$, and the $\mathrm{O}$ content ranges from $422.5 \mathrm{~g} \mathrm{~kg}^{-1}$ to $479 \mathrm{~g} \mathrm{~kg}^{-1}$. After corn straw returning, the content of $\mathrm{C}, \mathrm{H}$, and $\mathrm{N}$ in $\mathrm{HA}$ increased, while the content of $\mathrm{O}$ decreased. Among all the treatments, the SEDI treatment significantly increased the $\mathrm{C}, \mathrm{H}$, and $\mathrm{N}$ contents in the $20-40 \mathrm{~cm}$ depth. In the topsoil, the $\mathrm{H} / \mathrm{C}$ ratio increased in the trend of $\mathrm{SCR}>\mathrm{MBR}>\mathrm{SEDI}>\mathrm{CK}$, while the $\mathrm{O} / \mathrm{C}$ ratio decreased in the trend of $\mathrm{CK}>\mathrm{SEDI}>\mathrm{MBR}>\mathrm{SCR}$. In the subsoil, the

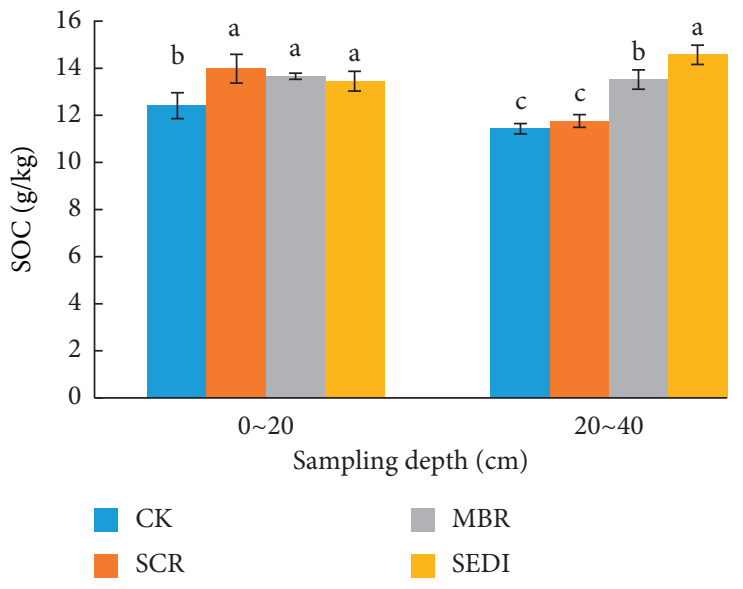

FIGURE 1: Effect of different treatments of corn straw on SOC.

$\mathrm{H} / \mathrm{C}$ ratio increased in the trend of SEDI $>\mathrm{MBR}>\mathrm{SCR}>\mathrm{CK}$, while the $\mathrm{O} / \mathrm{C}$ ratio decreased in the trend of $\mathrm{CK}>\mathrm{SCR}>\mathrm{MBR}>\mathrm{SEDI}$.

3.3. Three-Dimensional Fluorescence EEM Spectra of HA. The three-dimensional fluorescence spectroscopy of straw returning modes is displayed in Figures 2 and 3. All of the EEM fluorescence spectra of HA exhibited three fluorophores (peaks A-C). The three fluorophores were centered at the Em/Ex wavelength of 430-500/470-550 nm for peak A, 340-370/490-550 nm for peak B, and 270-340/ 460-550 nm for peak $C$, which may be related with the amount of humic substances. Among all the treatments, the highest fluorescence intensities of peaks $\mathrm{A}-\mathrm{C}$ were recorded under SEDI in the $20-40 \mathrm{~cm}$, and the lowest under CK in the $0-20 \mathrm{~cm}$. Generally, higher fluorescence intensity indicates greater proportions of hydroxyl, alkoxyl, and methoxyl [22]. The results showed that SEDI treatment had a slight increase in FI as compared with CK, implying that straw enrichment and deep incorporation were more conducive to improving the straw decomposition and soil HA formation than other treatments (Table 4).

3.4. ${ }^{13}$ C NMR Spectra of HA. The ${ }^{13} \mathrm{C}$ NMR spectra of HA for each treatment are reported in Figure 4 . The spectrum can be divided into 4 main resonance regions, namely, alkyl $\mathrm{C}$ (0 50 ppm), alkoxy C $(50 \sim 110 \mathrm{ppm})$, aromatic C (110 160 ppm), and carboxyl C (160 200 ppm) [23]. The peaks at $30 \mathrm{ppm}$ in the alkyl $\mathrm{C}$ region were assigned as- $\mathrm{CH} 2-$. The peak at 55 56 ppm in the $\mathrm{O}$-alkyl $\mathrm{C}$ region was assigned as methoxyl $\mathrm{C}$ in lignin. The peaks at $70 \sim 73 \mathrm{ppm}$ and 104 105 ppm were carbohydrate $C$ and hydrogen peroxide in polysaccharide, respectively. The peak at $128 \sim 130 \mathrm{ppm}$ in the aromatic $\mathrm{C}$ region was ascribed to aryl $\mathrm{C}$. The peak at 
TABLE 2: Effect of different treatments of corn straw on humic substances in black soil.

\begin{tabular}{lccccc}
\hline Depth $(\mathrm{cm})$ & Treatment & HA-C & FA-C & HM-C & PQ $(\%)$ \\
\hline \multirow{4}{*}{$0 \sim 20$} & CK & $3.19 \pm 0.10^{\mathrm{d}}$ & $1.89 \pm 0.10^{\mathrm{b}}$ & $5.31 \pm 0.16^{\mathrm{c}}$ & $62.78 \pm 0.01^{\mathrm{b}}$ \\
& SCR & $4.24 \pm 0.80^{\mathrm{a}}$ & $2.22 \pm 0.08^{\mathrm{a}}$ & $6.49 \pm 0.46^{\mathrm{a}}$ & $65.67 \pm 0.01^{\mathrm{a}}$ \\
& MBR & $3.96 \pm 0.18^{\mathrm{b}}$ & $2.20 \pm 0.13^{\mathrm{a}}$ & $6.16 \pm 0.12^{\mathrm{ab}}$ & $64.25 \pm 0.02^{\mathrm{a}}$ \\
& SEDI & $3.68 \pm 0.12^{\mathrm{c}}$ & $2.08 \pm 0.14^{\mathrm{a}}$ & $5.85 \pm 0.25^{\mathrm{b}}$ & $63.85 \pm 0.02^{\mathrm{a}}$ \\
$20 \sim 40$ & CK & $3.00 \pm 0.16^{\mathrm{c}}$ & $1.78 \pm 0.15^{\mathrm{a}}$ & $5.05 \pm 0.13^{\mathrm{c}}$ & $62.71 \pm 0.03^{\mathrm{a}}$ \\
& SCR & $3.22 \pm 0.22^{\mathrm{bc}}$ & $1.86 \pm 0.20^{\mathrm{a}}$ & $5.80 \pm 0.19^{\mathrm{b}}$ & $63.41 \pm 0.04^{\mathrm{a}}$ \\
& MBR & $3.60 \pm 0.10^{\mathrm{b}}$ & $2.03 \pm 0.20^{\mathrm{a}}$ & $6.01 \pm 0.21^{\mathrm{b}}$ & $63.90 \pm 0.04^{\mathrm{a}}$ \\
& SEDI & $4.03 \pm 0.14^{\mathrm{a}}$ & $2.13 \pm 0.20^{\mathrm{a}}$ & $6.64 \pm 0.38^{\mathrm{a}}$ & $65.39 \pm 0.03^{\mathrm{a}}$ \\
\hline
\end{tabular}

Note. CK: no straw application; SCR: straw mulching; MBR: straw deep ploughing; SEDI: straw enrichment and deep incorporation. There were significant differences between different letters representing different treatments $(p<0.05)$.

TABLE 3: Effect of straw returning to the field on HA element composition in soil.

\begin{tabular}{|c|c|c|c|c|c|c|c|}
\hline \multirow{2}{*}{ Depth $(\mathrm{cm})$} & \multirow{2}{*}{ Treatment } & \multicolumn{4}{|c|}{ Element content $\left(\mathrm{g} \cdot \mathrm{kg}^{-1}\right)$} & \multirow{2}{*}{$\mathrm{O} / \mathrm{C}$} & \multirow{2}{*}{$\mathrm{H} / \mathrm{C}$} \\
\hline & & $\mathrm{C}$ & $\mathrm{H}$ & $\mathrm{N}$ & $\mathrm{O}$ & & \\
\hline \multirow{4}{*}{$0 \sim 20$} & CK & $487.3 \pm 0.8^{\mathrm{d}}$ & $44.99 \pm 0.30^{\mathrm{d}}$ & $22.71 \pm 0.28^{\mathrm{d}}$ & $477.0 \pm 0.8^{\mathrm{a}}$ & $0.734 \pm 0.002^{\mathrm{a}}$ & $1.108 \pm 0.009^{c}$ \\
\hline & SCR & $512.9 \pm 0.7^{\mathrm{a}}$ & $49.54 \pm 0.06^{\mathrm{a}}$ & $27.88 \pm 0.10^{\mathrm{a}}$ & $422.5 \pm 0.5^{\mathrm{d}}$ & $0.618 \pm 0.001^{\mathrm{d}}$ & $1.159 \pm 0.001^{\mathrm{b}}$ \\
\hline & MBR & $495.1 \pm 0.9^{\mathrm{b}}$ & $47.97 \pm 0.10^{\mathrm{b}}$ & $25.70 \pm 0.12^{\mathrm{b}}$ & $435.2 \pm 0.9^{c}$ & $0646 \pm 0.001^{\mathrm{c}}$ & $1.140 \pm 0.002^{\mathrm{a}}$ \\
\hline & SEDI & $491.9 \pm 0.8^{\mathrm{c}}$ & $46.43 \pm 0.08 c$ & $23.42 \pm 0.09^{c}$ & $467.5 \pm 0.4^{\mathrm{b}}$ & $0.713 \pm 0001^{\mathrm{b}}$ & $1.133 \pm 0.002^{\mathrm{a}}$ \\
\hline \multirow{4}{*}{$20 \sim 40$} & CK & $482.1 \pm 0.9^{\mathrm{d}}$ & $43.21 \pm 0.90^{\mathrm{d}}$ & $21.52 \pm 0.10^{c}$ & $479.0 \pm 0.9^{\mathrm{a}}$ & $0.745 \pm 0.001^{\mathrm{a}}$ & $1.076 \pm 0.024^{\mathrm{c}}$ \\
\hline & SCR & $486.8 \pm 0.5^{\mathrm{c}}$ & $44.56 \pm 0.08^{\mathrm{c}}$ & $22.90 \pm 0.66^{\mathrm{b}}$ & $475.0 \pm 0.7^{\mathrm{b}}$ & $0.732 \pm 0.002^{b}$ & $1.099 \pm 0.001^{\mathrm{bc}}$ \\
\hline & MBR & $488.7 \pm 0.6^{\mathrm{b}}$ & $45.5 \pm 0.17^{\mathrm{b}}$ & $23.20 \pm 0.44^{\mathrm{b}}$ & $453.1 \pm 0.9^{c}$ & $0.695 \pm 0.001^{\mathrm{c}}$ & $1.117 \pm 0.005^{\mathrm{b}}$ \\
\hline & SEDI & $501.2 \pm 0.7^{\mathrm{a}}$ & $48.04 \pm 0.16^{\mathrm{a}}$ & $25.12 \pm 0.09^{\mathrm{a}}$ & $429.2 \pm 0.8^{\mathrm{d}}$ & $0.642 \pm 0.001^{\mathrm{d}}$ & $1.150 \pm 0.002^{\mathrm{a}}$ \\
\hline
\end{tabular}

Note. CK: no straw application; SCR: straw mulching; MBR: straw deep ploughing; SEDI: straw enrichment and deep incorporation. There were significant differences between different letters representing different treatments $(p<0.05)$.

$171 \sim 173 \mathrm{ppm}$ in the carbonyl $\mathrm{C}$ region was indicative of carboxylic acid, amide, and ester [24]. The shape of the spectrum of all treatments of HA shows similar tendencies; however, the absorption peak intensity is significantly different. It indicated that although HA has a similar structure, the HA structure changed after straw returning.

The relative intensity of the HA groups for different treatment is shown in Table 5. Compared with the CK treatment, all the straw returning treatments increased the alkyl C, whereas the O-alkyl C decreased. SCR, MBR, and SEDI treatments were $0.77 \%, 4.39 \%$, and $16.80 \%$ higher than CK treatment in alkyl C and 3.11\%, 5.26\%, and 8.24\% lower in $\mathrm{O}$-alkyl $\mathrm{C}$. These results showed that corn straw return was disadvantageous of accumulation for O-alkyl C; nevertheless, SEDI was beneficial to the formation of alkyl C. Moreover, SEDI treatments decreased aromatic C contents of soil HA by $1.72 \%$. Furthermore, compared with CK, SEDI treatments had no significant difference for carbonyl C; SCR treatment was $2.10 \%$ higher than CK treatment. However, MBR treatment decreased by $1.72 \%$. For the ratio of alkyl/O-alkyl and hydrophobic/hydrophilic, all the corn straw return treatments were higher than $\mathrm{CK}$, and SEDI had a higher increasing rate $(27.28 \%$ and $5.87 \%)$. The higher aliphatic $\mathrm{C}$ /aromatic $\mathrm{C}$ ratio indicated that $\mathrm{HA}$ is more aliphatic, and SEDI is more beneficial to improve the straw decomposition and HA formation than the other treatments.

\section{Discussion}

4.1. Corn Straw Returning Increased SOC and Humus C Contents. Soil stores most of the ecosystem carbon in the form of organic matter [25], and humus is the most abundant and important component of soil organic matter [7]. Thus, humus is a significant indicator to evaluate soil fertility [26]. Zhang et al. [27] observed that straw returning could increase the content of SOC and humus and improve soil fertility.

After three years, corn straw returning significantly increased SOC, HAC, FA-C, and HM-C contents in both soil depths (Table 2), consistent with previous studies [28-30]. Straw contains carbon, nitrogen, phosphorus, potassium, other nutrients [31] and a certain number of humus fractions [1]. Therefore, its application increases the content of humus $\mathrm{C}$ through stem and root exudates [32], which reduces the direct mineralization of soil organic carbon content. Lhadi et al. reported that the degradation of corn straw leads to the formation of humus [33]. The humus $\mathrm{C}$ persisted in the soil for a certain time, and then increased the soil carbon sequestration and humus composition content. It led to the increase of the HA/FA ratio, which indicated the humification degree of soil was deepened [3]. Among all the treatments, SEDI was more conductive to increasing SOC, $\mathrm{HAC}$, and FA-C contents in the subsoil (Table 2). Previous studies have shown that the organic carbon content of MBR is higher than that of SCR in the subsoil [34], due to the fact that the corn straw could not be fully mixed with soil under SCR treatment, and decreases its decomposition rate by soil microorganisms [35]. Compared with MBR, the process of deep burying of straw under the SEDI treatment disturbs the subsurface layer of the soil and stimulates microbial activity [36], increasing their metabolic rate [22] and increasing the soil easily oxidizable carbon [37]. The latter processes 


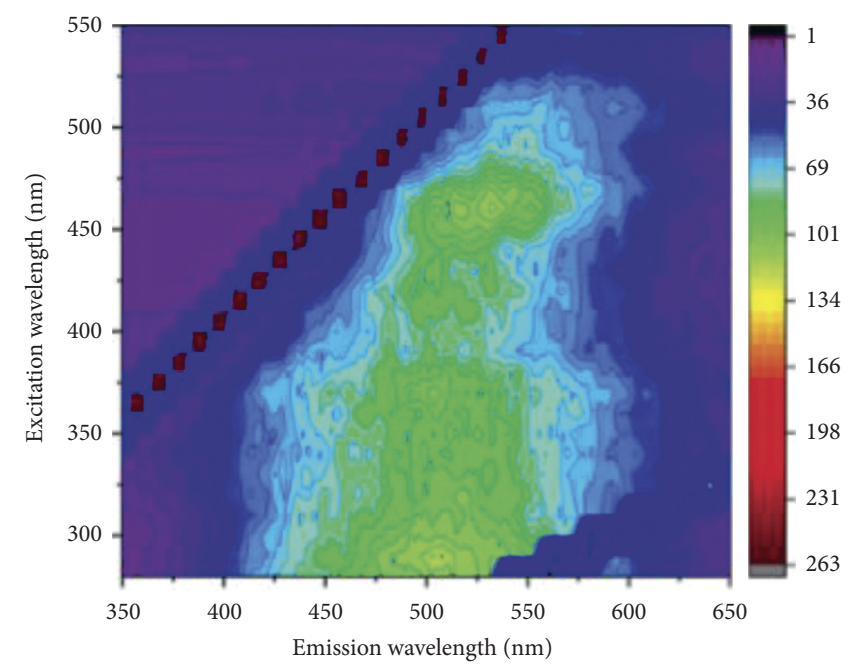

(a)

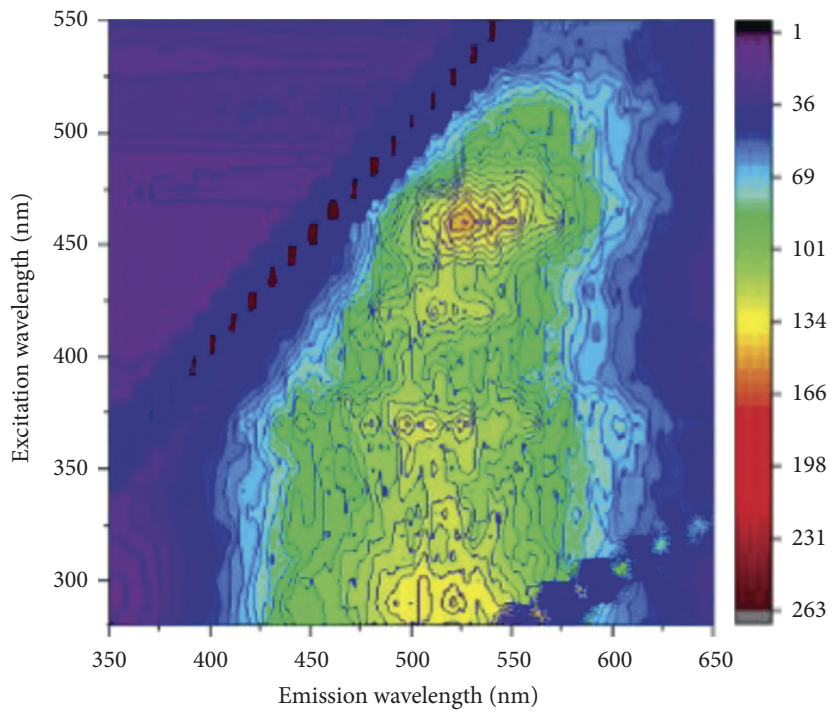

(c)

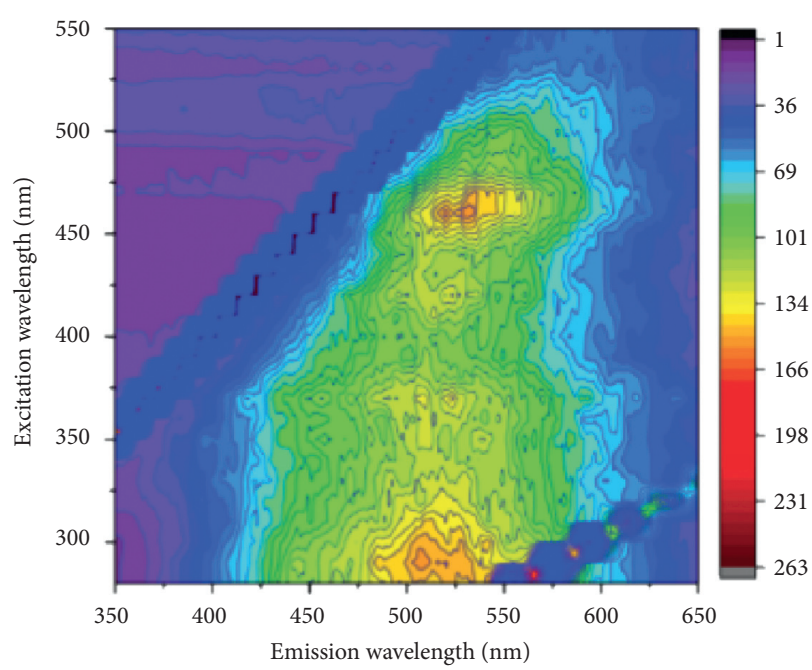

(b)

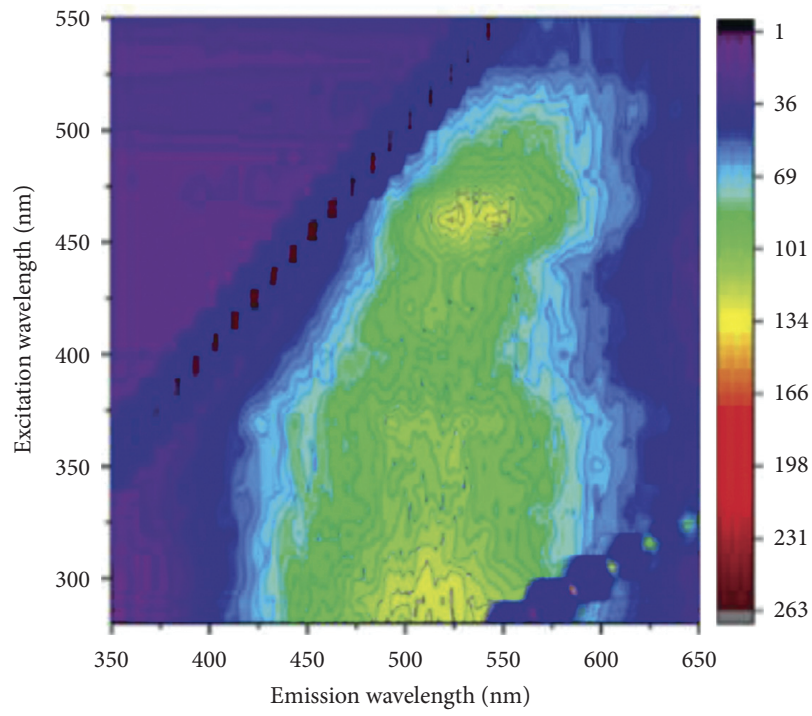

(d)

FIGURE 2: Fluorescence spectra of HA in different maize returning methods on topsoil. Note. CK: no straw application; SCR: straw mulching; MBR: straw deep ploughing; SEDI: straw enrichment and deep incorporation. (a) Topsoil: CK. (b) Topsoil: SCR. (c) Topsoil: MBR. (d) Topsoil: SEDI.

increase soil carbon sources. Straw returning to the field can promote a significant increase in the carbon content of HA, FA, and HM, while the PQ value increases slightly, but the change is not significant, indicating that the degree of soil maturation and fertility state of the soil transforms in the appropriate direction after straw returning [15].

\subsection{Corn Straw Returning Decreased the Oxidation Degree} and Condensation Degree of HA. The results showed that corn straw returning increased the $\mathrm{H} / \mathrm{C}$ molar ratio of $\mathrm{HA}$ and decreased the O/C molar ratio of HA (Table 3), which indicated that straw returning reduced the condensation degree and oxidation degree of HA structure and simplified the structure of HA. Chen et al. reported that the condensation degree and oxidation degree of HA structure in soil decreased after straw application [5], due to the promotion of microbial activity after straw application, and during the process of microbial metabolic decomposition, HA with complex structure in soil was decomposed, which reduced the stability of $\mathrm{HA}$ structure [38]. In addition, the number of newly formed HA oxygen-containing functional groups in the process of straw decomposition was less [39], which reduced the degree of oxidation of $\mathrm{HA}$ and made the structure of HA be simpler and younger.

4.3. Corn Straw Returning Increased the Hydrophobicity of $H A$. Fluorescence spectroscopy can be used to measure the structure and properties of compounds and determine the structure of functional groups of humus [40, 41]. Our research has shown that the hydrophobicity of HA structure of the soil was enhanced after the straw returning. In our study, straw application compared with CK increased the 


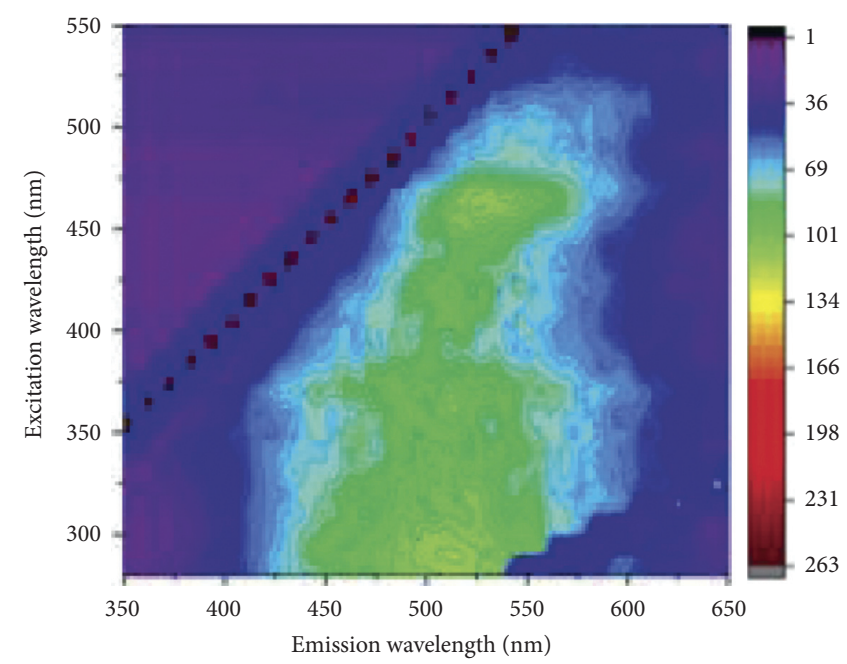

(a)

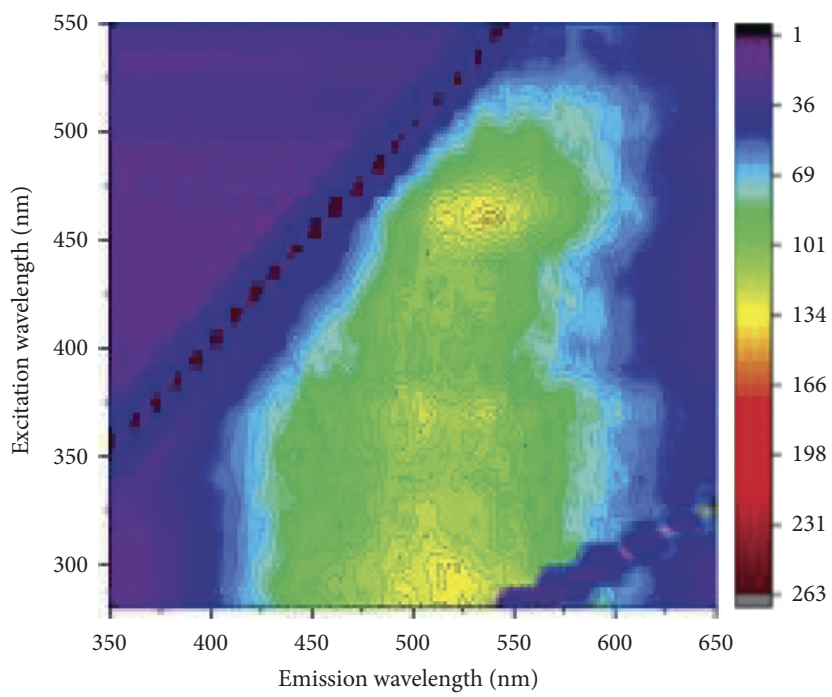

(c)

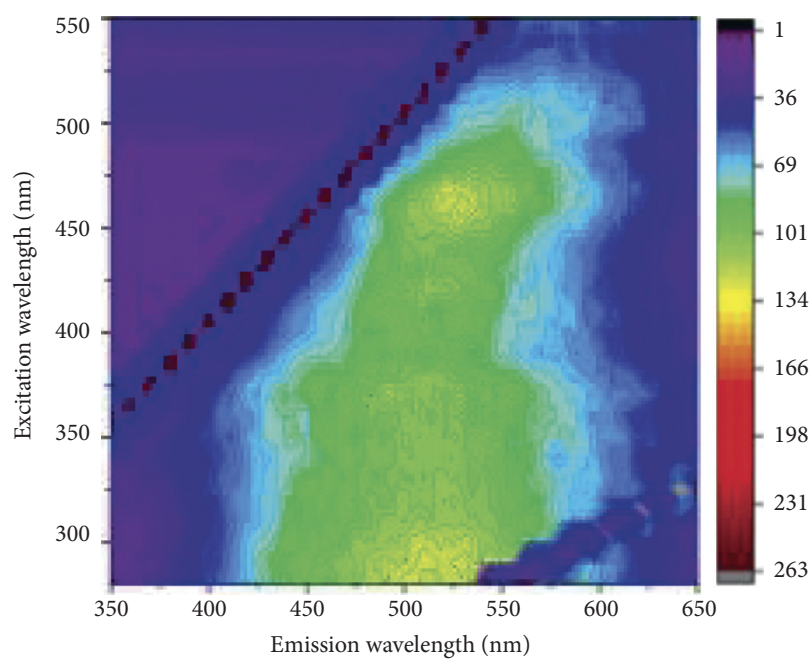

(b)

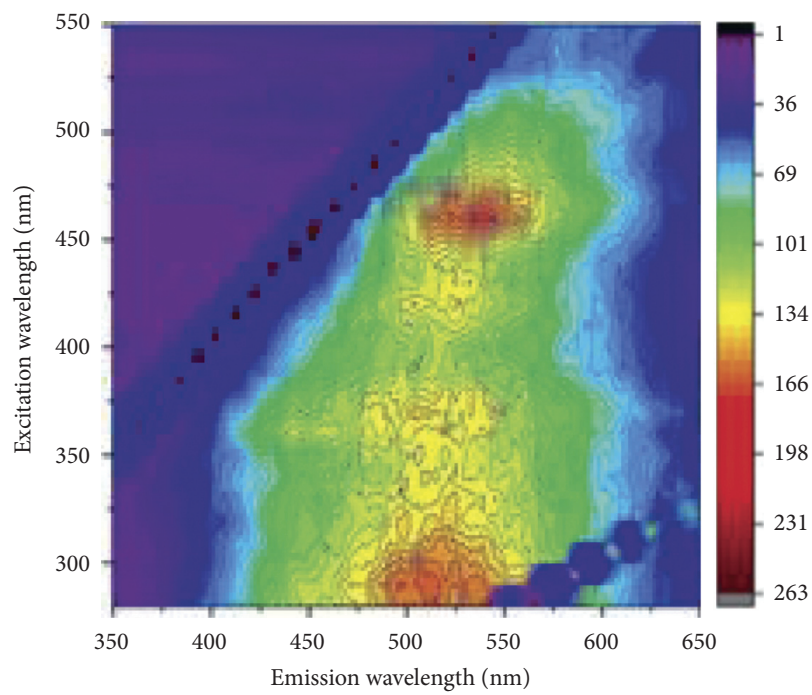

(d)

FIgURE 3: Fluorescence spectra of HA in different maize returning methods on subsoil. Note. CK: no straw application; SCR: straw mulching; MBR: straw deep ploughing; SEDI: straw enrichment and deep incorporation. (a) Subsoil: CK. (b) Subsoil: SCR. (c) Subsoil: MBR. (d) Subsoil: SEDI.

TABLE 4: Excitation (Ex)/emission (Em) wavelength and fluorescence intensity (FI) of peaks in humic acid after different corn straw return modes.

\begin{tabular}{|c|c|c|c|c|c|c|c|}
\hline \multirow{2}{*}{ Soil depth $(\mathrm{cm})$} & \multirow{2}{*}{ Treatment } & \multicolumn{2}{|c|}{ Peak A } & \multicolumn{2}{|c|}{ Peak B } & \multicolumn{2}{|c|}{ Peak C } \\
\hline & & $\mathrm{Ex} / \mathrm{Em}$ & Intensity (a.u.) & $\mathrm{Ex} / \mathrm{Em}$ & Intensity (a.u.) & $\mathrm{Ex} / \mathrm{Em}$ & Intensity (a.u.) \\
\hline \multirow{4}{*}{$0 \sim 20$} & $\mathrm{CK}$ & $460 / 524$ & 115.02 & $370 / 504$ & 105.00 & $290 / 503$ & 117.84 \\
\hline & SCR & $460 / 531$ & 154.52 & $370 / 523$ & 136.33 & $290 / 508$ & 153.54 \\
\hline & MBR & $460 / 523$ & 149.63 & $370 / 498$ & 135.81 & $290 / 521$ & 141.71 \\
\hline & SEDI & $460 / 528$ & 130.56 & $370 / 495$ & 117.72 & $290 / 523$ & 129.32 \\
\hline \multirow{4}{*}{$20 \sim 40$} & CK & $460 / 528$ & 112.86 & $370 / 511$ & 112.61 & $290 / 515$ & 114.30 \\
\hline & SCR & $460 / 529$ & 125.33 & $370 / 493$ & 114.19 & $290 / 520$ & 120.14 \\
\hline & MBR & $460 / 537$ & 144.73 & $370 / 505.6$ & 126.12 & $300 / 522$ & 135.99 \\
\hline & SEDI & $460 / 535$ & 172.34 & $370 / 506$ & 143.47 & $290 / 509$ & 164.00 \\
\hline
\end{tabular}

Note. CK: no straw application; SCR: straw mulching; MBR: straw deep ploughing; SEDI: straw enrichment and deep incorporation.

intensities of peaks $\mathrm{A}$ to $\mathrm{C}$, which indicates that the application of corn straw contains more electron-donating substituents such as hydroxyl, methoxy, and amino [42], and they can increase the fluorescence intensity by increasing the transition probability between the singlet state and the ground state [43]. Gao et al. have shown that straw returning 


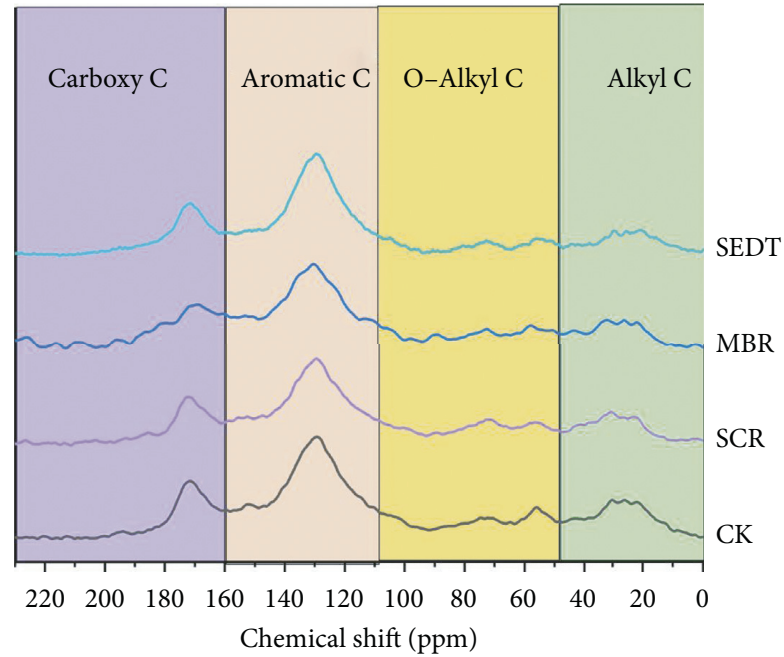

FIgURE $4:{ }^{13} \mathrm{C}$ CPMAS NMR spectra of HA in different maize returning methods. Note. CK: no straw application; SCR: straw mulching; MBR: straw deep ploughing; SEDI: straw enrichment and deep incorporation. There were significant differences between different letters representing different treatments $(p<0.05)$.

TABle 5: Relative intensity (\%) of different chemical shift intervals from ${ }^{13} \mathrm{C}$ CPMAS NMR spectra of HA examined.

\begin{tabular}{lccccccc}
\hline Treatment & $\begin{array}{c}\text { Carbonyl C (\%) } \\
(160-230 \mathrm{ppm})\end{array}$ & $\begin{array}{c}\text { Aromatic C (\%) } \\
(110-160 \mathrm{ppm})\end{array}$ & $\begin{array}{c}\text { O-Alkyl C (\%) } \\
(50-110 \mathrm{ppm})\end{array}$ & $\begin{array}{c}\text { Alkyl C (\%) } \\
(0-50 \mathrm{ppm})\end{array}$ & $\begin{array}{c}\text { Alkyl C/ } \\
\text { O-alkyl C }\end{array}$ & $\begin{array}{c}\text { Aliphatic C/ } \\
\text { aromatic C }\end{array}$ & $\begin{array}{c}\text { Hydrophobic C/ } \\
\text { hydrophilic C }\end{array}$ \\
\hline CK & 18.58 & 53.98 & 14.45 & 12.98 & 0.898 & 0.508 & 2.027 \\
SCR & 18.97 & 53.96 & 14.00 & 13.08 & 0.934 & 0.502 & 2.034 \\
MBR & 18.26 & 54.49 & 13.69 & 13.55 & 0.99 & 0.500 & 2.129 \\
SEDI & 18.53 & 53.05 & 13.26 & 15.16 & 1.143 & 0.536 & 2.146 \\
\hline
\end{tabular}

Note. CK: no straw application; SCR: straw mulching; MBR: straw deep ploughing; SEDI: straw enrichment and deep incorporation.

to the field can improve the soil and found that the soil had a higher content of alkoxy carbon and methyl carbon $[22,44]$, while methyl $\mathrm{C}$ was converted from lignin polymerization [45] and was a hydrophobic substance. Therefore, returning straw enhances the hydrophobicity of HA.

Considering the complex peak assignment in the elemental analysis and fluorescence spectroscopy of HA, we evaluated the HA structural characteristics further using the solid-state ${ }^{13} \mathrm{C}$ CPMAS NMR technique. Different ways of returning straw to the field led to different changes in the structure of functional groups, mainly manifested as changes in aromatic carbon, alkyl carbon, alkoxy carbon, and carboxyl carbon. Alkyl C (aliphatic compound, methyl C, etc.) is a carbon compound difficult to degrade in soil. Thus, the application of straw results in the increase of alkyl C community and microbial structure [46]. The decomposition of $\mathrm{O}$-alkyl $\mathrm{C}$ is mainly due to the fact that cellulose and hemicellulose in plant residues are easily metabolized by microorganisms to utilize organic carbon functional groups. The relative content of alkoxy $\mathrm{C}$ slightly increases after straw returning, while during the rapid phase of corn stalk decomposing, the $\mathrm{O}$-alkyl $\mathrm{C}$ in the plant residues will be quickly lost into the soil, resulting in a relatively low content of alkoxy C [47]. Aromatic C (mainly from tannin and lignin) is relatively stable. The decrease of the structure in SEDI may be due to the aerobic degradation of lignin by white rot and brown rot fungi through dehydration, demethylation, or cleavage of $\beta-\mathrm{O}-4$ bonds [48]. Carboxyl carbons mainly come from carboxylic acids, amides, and esters [49]. The increase in carboxyl C under SCR treatment might be related to the oxidation of lignin side chains and polysaccharides [39]. The hydrophobicity of HA was determined by the ratio of hydrophobic $\mathrm{C}$ (aromatic $\mathrm{C}$ and alkyl C) to hydrophilic C (alkoxy C and carboxyl C). The higher the ratio, the stronger the hydrophobicity and the stronger the stability of soil HA [50].

4.4. Effects of Different Returning Methods on the Soil HA Structure. Studies have shown that hydrophobicity was meaningful for maintaining the stability of soil organic carbon [50]. Our results showed that straw return enhances the hydrophobicity of HA structure, and SEDI treatment was the most effective (Table 5). Studies have shown that the ratio of high alkyl $\mathrm{C}$ and low aromatic $\mathrm{C}$ makes the soil organic matter younger [51]. This implies that $\mathrm{HA}$ is younger under SEDI treatment. The higher aliphatic C/ aromatic $\mathrm{C}$ ratio showed (Table 5) that HA was highly aliphatic under SEDI treatment, which made the structure of HA simpler. On the contrary, the aromaticity was enhanced under the MBR and SCR treatment, demonstrating a more complex HA structure. Therefore, straw buried in the subsurface of soil increases the soil oxidizable carbon, stimulates the microbial activity, speeds up the metabolic rate of microorganisms, and promotes the decomposition of HA. 


\section{Conclusion}

In this 3-year study, ${ }^{13} \mathrm{C}$ NMR spectroscopy and three-dimensional fluorescence spectroscopy were adapted to analyze the structure of soil HA after straw returning. The study concludes the following:

(i) Adding corn straw into soil significantly increased SOC content and humus composition. Compared to all the rest treatments, SEDI accumulated the largest quantities of SOC and C contents of humic acid, especially in the subsurface soil layer.

(ii) Among the four treatments, SEDI was the most conducive way to enhance the hydrophobicity of the HA structure, which made it more stable, and improve the soil carbon sequestration capacity.

\section{Data Availability}

All the data generated or analyzed during this study are available within the article.

\section{Conflicts of Interest}

The authors declare that they have no conflicts of interest.

\section{Acknowledgments}

This study was supported by the National Key Research and Development Program of China (2017YFD0200601), the Key Research and Development Program of Jilin Province (20200402098NC), and the National Natural Science Foundation of China (42077022). The authors thank Dr. L. C. Ming and Zhang. Y. Feng for their valuable advice on ${ }^{13} \mathrm{C}$ NMR spectroscopy analysis.

\section{References}

[1] X. Zhang, S. Dou, B. S. Ndzelu, X. W. Guan, B. Y. Zhang, and Y. Bai, "Effects of different corn straw amendments on humus composition and structural characteristics of humic acid in black soil," Communications in Soil Science and Plant Analysis, vol. 51, no. 1, pp. 107-117, 2020.

[2] A. Chatterjee, "Annual crop residue production and nutrient replacement costs for bioenergy feedstock production in United States," Agronomy Journal, vol. 105, no. 3, pp. 685-692, 2013.

[3] P. Cong, Fertilization Effect and Mechanism of Subsoil under High Dosage Straw Returning in Black Soil of Northeast China, Chinese Academy of Agricultural Sciences, Beijing, China, 2019.

[4] H. Zou, "Effect of different straw return years on humus composition of soil," Chinese Journal of Soil Science, vol. 44, no. 6, pp. 1398-1402, 2013.

[5] X. Chen, J. Wu, and Y. Opoku-Kwanowaa, "Effects of returning granular corn straw on soil humus composition and humic acid structure characteristics in saline-alkali soil," Sustainability, vol. 12, no. 3, p. 1005, 2020.

[6] F. Adani, M. Spagnol, and K. G. J. Nierop, "Biochemical origin and refractory properties of humic acid extracted from maize plants: the contribution of lignin," Biogeochemistry, vol. 82, no. 1, pp. 55-65, 2007.
[7] G. Brunetti, C. Plaza, C. E. Clapp, and N. Senesi, "Compositional and functional features of humic acids from organic amendments and amended soils in Minnesota, USA," Soil Biology and Biochemistry, vol. 39, no. 6, pp. 1355-1365, 2007.

[8] Y. Qu and B. Feng, "Straw mulching improved yield of field buckwheat (Fagopyrum) by increasing water-temperature use and soil carbon in rain-fed farmland," Acta Ecologica Sinica, vol. 11, 2020.

[9] B. S. Ndzelu, S. Dou, and X. Zhang, "Changes in soil humus composition and humic acid structural characteristics under different corn straw returning modes," Soil Research, vol. 58, no. 5, pp. 452-460, 2020.

[10] L. Zhuang, B. Huang, F. Jiang et al., "Straw returning and its effective returning method: research progress," Chinese Agricultural Science Bulletin, vol. 35, no. 22, pp. 38-41, 2019.

[11] S. M. Zuber, G. D. Behnke, E. D. Nafziger, and M. B. Villamil, "Crop rotation and tillage effects on soil physical and chemical properties in Illinois," Agronomy Journal, vol. 107, no. 3, pp. 971-978, 2015.

[12] P. Jiang, M. Rong, Q. Zhang et al., "Effects of increasing soil fertility and maize output by manure the maize straw with different returning ways to upland soil," Soil Fertilizer, vol. 3, pp. 7-9, 2004.

[13] X. Liu, "Effects of deep loosening and deep straw returning on soil organic carbon and its. Active fractions in black soil," Chinese Journal of Soil Science, vol. 50, no. 03, pp. 602-608, 2019.

[14] T. Cui, Z. Li, and S. Wang, "Effects of in-situ straw decomposition on composition of humus and structure of humic acid at different soil depths," Journal of Soils and Sediments, vol. 17, no. 10, pp. 2391-2399, 2017.

[15] Y. Zhang, "Effect of deep incorporation of corn stover combined chemical fertilizer on composition of soil humus and structure of humic acid in soil," Acta Pedologica Sinica, vol. 53, no. 03, pp. 694-702, 2016.

[16] Y. S. S. Al-Faiyz, "CPMAS 13C NMR characterization of humic acids from composted agricultural Saudi waste," Arabian Journal of Chemistry, vol. 10, pp. 839-853, 2017.

[17] X. Chen, Effect of Straw Incorporation on Elemental Composition and Chemical Structure of Soil Organic Matter, Anhui Agricultural University, Hefei, China, 2016.

[18] R. Lu, Soil Agricultural Chemistry Analysis Method, China Agricultural Science and Technology Press, Beijing, China, 2000.

[19] T. Anđelković, D. Anđelković, J. Perović et al., "Decrease of oxygen interference on humic acid structure alteration during isolation," Facta Universitatis-Series: Physics, Chemistry and Technology, vol. 2, no. 3, pp. 163-171, 2001.

[20] S. Kuwatsuka, A. Watanabe, K. Itoh, and S. Arai, "Comparison of two methods of preparation of humic and fulvic acids, IHSS method and NAGOYA method," Soil Science and Plant Nutrition, vol. 38, no. 1, pp. 23-30, 1992.

[21] P. Conte, "Quantitative differences in evaluating soil humic substances by liquid-and solid-state 13C-NMR spectroscopy," Geoderma, vol. 80, no. 3-4, pp. 339-352, 1997.

[22] J. Hu, J. Wu, X. Qu, and J. Li, "Effects of organic wastes on structural characterizations of humic acid in semiarid soil under plastic mulched drip irrigation," Chemosphere, vol. 200, pp. 313-321, 2018.

[23] M. Schnitzer and C. M. Preston, "Analysis of humic acids by solution and solid-state carbon-13 nuclear magnetic resonance," Soil Science Society of America Journal, vol. 50, no. 2, pp. 326-331, 1986. 
[24] L. Li, W. Huang, P. a. Peng, G. Sheng, and J. Fu, "Chemical and molecular heterogeneity of humic acids repetitively extracted from a peat," Soil Science Society of America Journal, vol. 67, no. 3, pp. 740-746, 2003.

[25] D. H. Wall, "Biodiversity and ecosystem functioning," Bioscience, vol. 49, no. 2, pp. 107-108, 1999.

[26] S. Salmon, "Changes in humus forms and soil animal communities in two developmental phases of Norway spruce on an acidic substrate," Forest Ecology \& Management, vol. 237, no. 1-3, pp. 0-56, 2006.

[27] J. Zhang, Y. Wei, J. Liu et al., "Effects of maize straw and its biochar application on organic and humic carbon in waterstable aggregates of a Mollisol in Northeast China: a five-year field experiment," Soil and Tillage Research, vol. 190, pp. 1-9, 2019.

[28] N. Liu, "Depth of straw incorporation significantly alters crop yield, soil organic carbon and total nitrogen in the North China Plain," Soil and Tillage Research, vol. 205, 2021.

[29] A. L. Hammerbeck, S. J. Stetson, S. L. Osborne, T. E. Schumacher, and J. L. Pikul, "Corn residue removal impact on soil aggregates in a No-till corn/soybean rotation," Soil Science Society of America Journal, vol. 76, no. 4, pp. 1390-1398, 2012.

[30] J. Liu, "Effects of returning stalks into field on soil humus composition of continuous cropping cotton field," Scientia Agricultura Sinica, vol. 48, no. 2, pp. 293-302, 2015.

[31] P. Wang, "Effect of sweet corn straw returning to the field on soil fertility, yield and benefit," Meteorological \& Environmental Research, vol. 7, no. 4, 2016.

[32] S. Ma, Z. Kan, J. Qi, and H. Zhang, "Effects of straw return mode on soil aggregates and associated carbon in the north China plain," Agronomy, vol. 10, no. 1, p. 61, 2020.

[33] E. K. Lhadi, H. Tazi, M. Aylaj, P. L. Genevini, and F. Adani, "Organic matter evolution during co-composting of the organic fraction of municipal waste and poultry manure," Bioresource Technology, vol. 97, no. 16, pp. 2117-2123, 2006.

[34] N. Liang, G. Cai, F. Jiang et al., "Effect of different maize straw-returning modes on the fertility of black soil," Journal of Maize Sciences, vol. 24, no. 6, pp. 107-113, 2016.

[35] H. Wang, D. Wang, and H. Tian, "Effect of straw-returning on the storage and distribution of different active fractions of soil organic carbon," Chinese Journal of Applied Ecology, vol. 25, no. 12, pp. 3491-3498, 2014.

[36] I. Lobe, "Aggregate dynamics and associated soil organic matter contents as influenced by prolonged arable cropping in the South African Highveld," Geoderma, vol. 162, no. 3-4, pp. 251-259, 2011.

[37] C. Li, L. Gao, P. Jiang et al., "Research on mechanized Technology of returning corn stalks to field," Modern Agricultural Machinery, vol. 5, pp. 43-44, 2019.

[38] S. Abiven, S. Menasseri, and C. Chenu, "The effects of organic inputs over time on soil aggregate stability - a literature analysis," Soil Biology and Biochemistry, vol. 41, no. 1, pp. 1-12, 2009.

[39] M. Tamura, V. Suseela, M. Simpson, B. Powell, and N. Tharayil, "Plant litter chemistry alters the content and composition of organic carbon associated with soil mineral and aggregate fractions in invaded ecosystems," Global Change Biology, vol. 23, no. 10, pp. 4002-4018, 2017.

[40] D. M. B. P. Milori, L. Martin-Neto, C. Bayer, J. Mielniczuk, and V. S. Bagnato, "Humification degree of soil humic acids determined by fluorescence spectroscopy," Soil Science, vol. 167, no. 11, pp. 739-749, 2002.
[41] L. Pospíšilová, "Effect of selected organic materials on soil humic acids chemical properties," Environmental Research, vol. 187, 2020.

[42] W. Zech, "Factors controlling humification and mineralization of soil organic matter in the tropics," Ganoderma, vol. 79, no. 1, pp. 117-161, 1997.

[43] N. Senesi, T. M. Miano, M. R. Provenzano, and G. Brunetti, "Characterization, differentiation, and classification of humic substances by fluorescence spectroscopy," Soil Science, vol. 152, no. 4, pp. 259-271, 1991.

[44] J. Gao, S. Dou, and Z. Wang, "Structural analysis of humic acid in soil at different corn straw returning modes through fluorescence spectroscopy and infrared spectroscopy," International Journal of Analytical Chemistry, vol. 2019, Article ID 1086324, 9 pages, 2019.

[45] K. Wang, D. Xu, F. Ding et al., "Process of plant residue transforming into soil organic matter and mechanism of its stabilization: a review," Acta Pedologica Sinica, vol. 56, no. 3, pp. 528-540, 2019.

[46] G. Wu, H. Wang, M.. Jiang et al., "Study on humic acids in the soil applied with corn stalk by spectroscopy measurements," Scientia Agricultura Sinica, vol. 38, no. 7, p. 139401400, 2005.

[47] N. J. Mathers and Z. Xu, "Solid-state 13C NMR spectroscopy: characterization of soil organic matter under two contrasting residue management regimes in a 2-year-old pine plantation of subtropical Australia," Geoderma, vol. 114, no. 1-2, pp. 19-31, 2003.

[48] S. Derenne and C. Largeau, "A review of some important families of refractory macromolecules: composition, origin, and fate in soils and sediments," Soil Science, vol. 166, no. 1, 2001.

[49] N. Li, M. Sheng, Y. You et al., "Advancement in research on application of 13C NMR techniques to exploration of chemical structure of soil organic matter," Acta Pedologica Sinica, vol. 56, no. 4, pp. 796-812, 2019.

[50] S. Bai, M. Luo, H. Li et al., "Chemical composition and structural features of soil organic carbon (SOC)in plantation," Journal of Southwest Minzu University (Natural Science Edition), vol. 43, no. 5, pp. 474-479, 2017.

[51] M. von Lützow, I. Kögel-Knabner, K. Ekschmitt et al., "SOM fractionation methods: relevance to functional pools and to stabilization mechanisms," Soil Biology and Biochemistry, vol. 39, no. 9, pp. 2183-2207, 2007. 